\title{
Artists in the Eyes of Children - Semiotic Analysis of the Meanings about Artists Constructed by Children
}

\begin{abstract}
The problem around which this study was constructed is the contemporary art and a person, who creates this art - an artist, and their authentic perception by the child. A modern vision of the child too often shows the artist in a distorted, incomplete or reduced way. This kind of children knowledge, based on the patterns and stereotypes, reduces the reflectivity of children, unnecessarily distorts their judgment and closes the road ahead to a full and critical participation in the world. The study is based on the analysis of interviews and children's drawings centered around the perception of the profile of an artist by children. It results from the analysis of the research material gathered during the study that this is a stereotypical vision, and the artist is still associated with a person who remains beyond the reach of "normal" society.

The conducted research shows the diversity of the types of meanings that children aged 5-7 attribute to the term "artist" and "artistry". The naive ideas on this subject created by children prove to be a collection of beliefs of a partially common and often completely different nature. For a pedagogue, the ultimate purpose of the research is to obtain knowledge which will allow effective changes in education, in this case, in art education. The investigation of meanings which children attribute to concepts concerning the artistic phenomena may allow to create a strategy of transmission of knowledge of art history and to design the creative activities connected with the broadly-understood visual arts.
\end{abstract}

\section{Keywords:}

children, artists, semiotic analysis, drawings, interviews, art, children's meanings, common concepts of reality com.

Faculty of Social Science, University of Gdańsk, Poland, E-MAIL: sienkiewiczus@gmail.

2 III High School in Gdansk, Poland. 


\section{INTRODUCTION}

Arts education of the youngest has been a widely discussed issue, debated in various academic circles. Questions posed by both pedagogues and psychologists as well as by parents and teachers concern the need for development of productiveness and creativity, formation of the child's personality and sensitivity by the education through art. Works pertaining to these issues are, among others, books by Wiesława Limont and Kamilla Nielek-Zawadzka (2005), Hanna Krauze-Sikorska (2006), Małgorzata Karczmarzyk and Anna Wasilewska (2013, 2015), Melissa Menzer (2015), etc.

And yet, despite so many works pointing to significance of art classes for the child's development, in modern Polish school arts education is still being treated marginally, with - which is vital - exercises related to divergent thinking outnumber exercises involving divergent thinking. For it might be the other way round.

The problem around which this study was constructed is the contemporary art and a person, who creates this art - an artist, and their authentic perception by the child. A modern vision of the child too often shows the artist in a distorted, incomplete or reduced way. This kind of naive knowledge, based on the patterns and stereotypes, reduces the reflectivity of children, unnecessarily distorts their judgment and closes the road ahead to a full and critical participation in the world. This text focuses on the theme of transmission of the meanings of children on the perception of a person who is an artist. The study is based on the analysis of interviews and children's drawings centered around the perception of the profile of an artist by children. It results from the analysis of the research material gathered during the study that this is a stereotypical vision, and the artist is still associated with a person who remains beyond the reach of "normal" society.

\section{METHODOLOGY}

Our research is based on the quality methodology. The group selected for the research purposes is 13 seven-year-old children. Children participating in the study come from the district of Gdańsk - Chełm, and from two towns Kowal and Pruszcz Gdański. The basic research problems are:

- What meanings do seven-year-old children give to the term "artist"?

- What distinguishing features, according to children, should an artist have?

- How can the media influence the shaping of the meanings of children about the artist? 
- How can the aestheticization influence the shaping of the meanings of children about the artist?

Each child was examined individually. The research consisted in creating a drawing by a child, and then the child was asked in an individual interview (technique) about the meanings given to particular symbols from his/her drawing. The test tools were A4 pages, 12 pencil crayons.

Due to the fact that: semiotics examines all cultural phenomena as if they were sign systems, and assuming a hypothesis that cultural phenomena are indeed sign systems, they are also communication phenomena (Eco, 2003, pp. 35), it is possible to state that all kinds of communication, either verbal or nonverbal, are based on semiotics. Therefore, pictorial communication owns certain forms which according to a semiotic perspective can be called signs, creating a specific text - painting meant to be read by a receiver. In the next part of this article we would like to analyze the significance of painting and phenomena concerning differentiating and operationalizing of a pictorial message.

Due to the above-mentioned perspective, it is worthwhile to pose the following research questions: What instances of painting might be significant to the child?

The applied method will be author method of examination of meanings of children’s drawing created by Małgorzata Karczmarzyk (2014). Due to the need to take into consideration the complexity of factors which could influence the drawing and oral expression of a child, as well as the complicated relationships among those factors, it is necessary to apply a method which will allow a possibly open and reflective research approach and semiotics proposes precisely such an approach. The below-presented diagram presents a triad which constitutes the foundation of research concerning the meanings of children's drawings.

For Charles Sanders Peirce (1997, p. 137) the concept of a sign is crucial and determines almost all. His conception sees a sign as a tripartite unity:

1) representamen (first correlate of a triadic relation),

2) object (second correlate of a triadic relation),

3) interpretant (third correlate of a triadic relation).

Following Peirce's theory we use his correlates, but we also introduce others terms connected with this area such as: a drawing-message, a drawing-text or a pictorial text, the semantic content, drawing communication. 


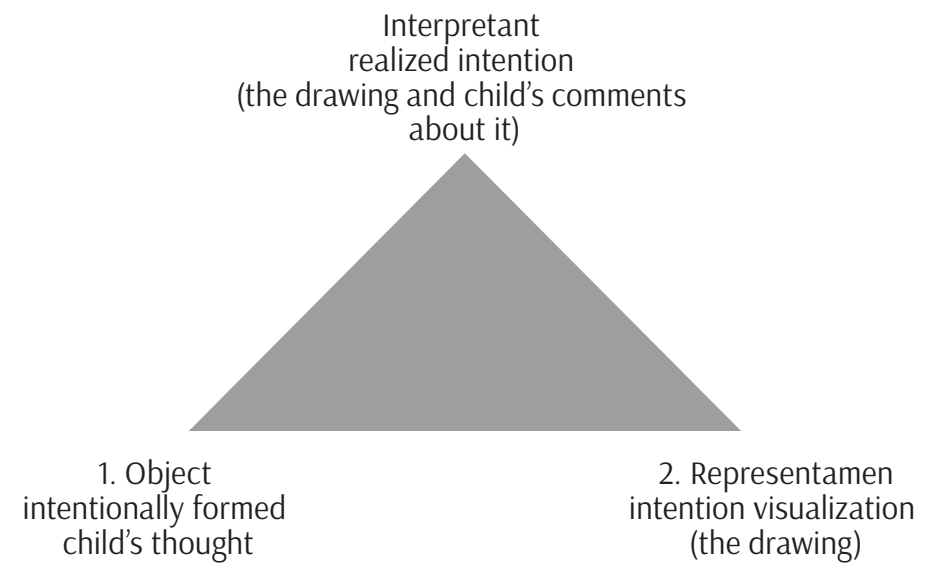

Diagram 3. Triad - the basis of research of meanings of drawings: children

According to the above model, the semiotic analysis in our research includes (Karczmarzyk, 2010, pp. 172-176):

Object. An object refers to the intentionally formed and thought of a child who responds to my question. The intention forming the message and laying its foundation which is given by a child may be different due to the addressee. We may assume that a child communicating through the iconic sign "says" something different to his/her parents than to his/her teachers.

Symbol (representamen). The way in which a child presents his/her family in the drawing, because of the object, would be a representation of an intention. Everything that appears in the piece of paper would be its visualization - as we may suspect sometimes different due to the receivers of a drawing.

Interpretant. We call an interpretant a child's interpretation; that means the interpretation given to a drawing by a child. Having finished his/her work, every child described the content of the drawing. We asked them, among other questions: What does this (a particular element and the whole drawing) mean? Why do you want to give/show this drawing to your parents/ other adults? And the child was encouraged to verbalize the meaning of the drawing. This verbalization allowed us later to compare these meanings with those given by its receivers.

For the purposes of the conducted research of the meanings attributed by children to the term "artist", we have applied open, in-depth interview and document analysis (in this case the semiotic analysis of children's drawings) (Karczmarzyk, 2010, pp. 172-176). 


\section{ANALYSIS OF RESEARCH MATERIAL - EXAMPLES}

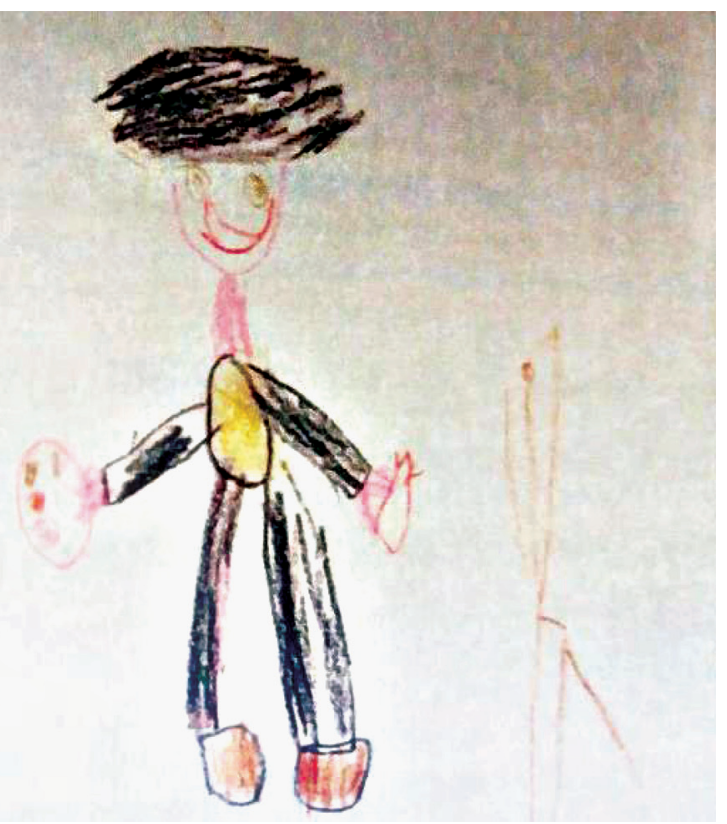

\section{Drawing 1. Marek, 7 years old}

To depict an artist, Marek used a characteristic element of the outfit, which is a beret. A beret is a bohemian symbol, a graphic distinguisher of painters known to children from media messages, e.g. "Reksio, the painter". An additional prop, which is to testify to the profession performed by the artist, is the easel. The meaning drawn by the child therefore depends on the symbolic "clothing" of the artist in a kind of uniform. The figure of the artist seen in this way is not related to any personal experience, so it is a purely cultural creation. Below there is a fragment of the interview with the author of the above drawing:

B: what's on his head?

M: such a beret

B: why?

M: because some artists wear it in this way, they dress like that

B: what does this outfit mean?

M: I do not know exactly

B: what do you think?

M: hmmm .... a bit old, so as not to ...get dirty, lest it be ... on the old one. 
Although it is not explicitly articulated, it can be assumed that the attire of an artist is associated with their nonchalance. An additional justification for this outfit may be the boy's own experiences - fear of destroying clothes during artistic activities.

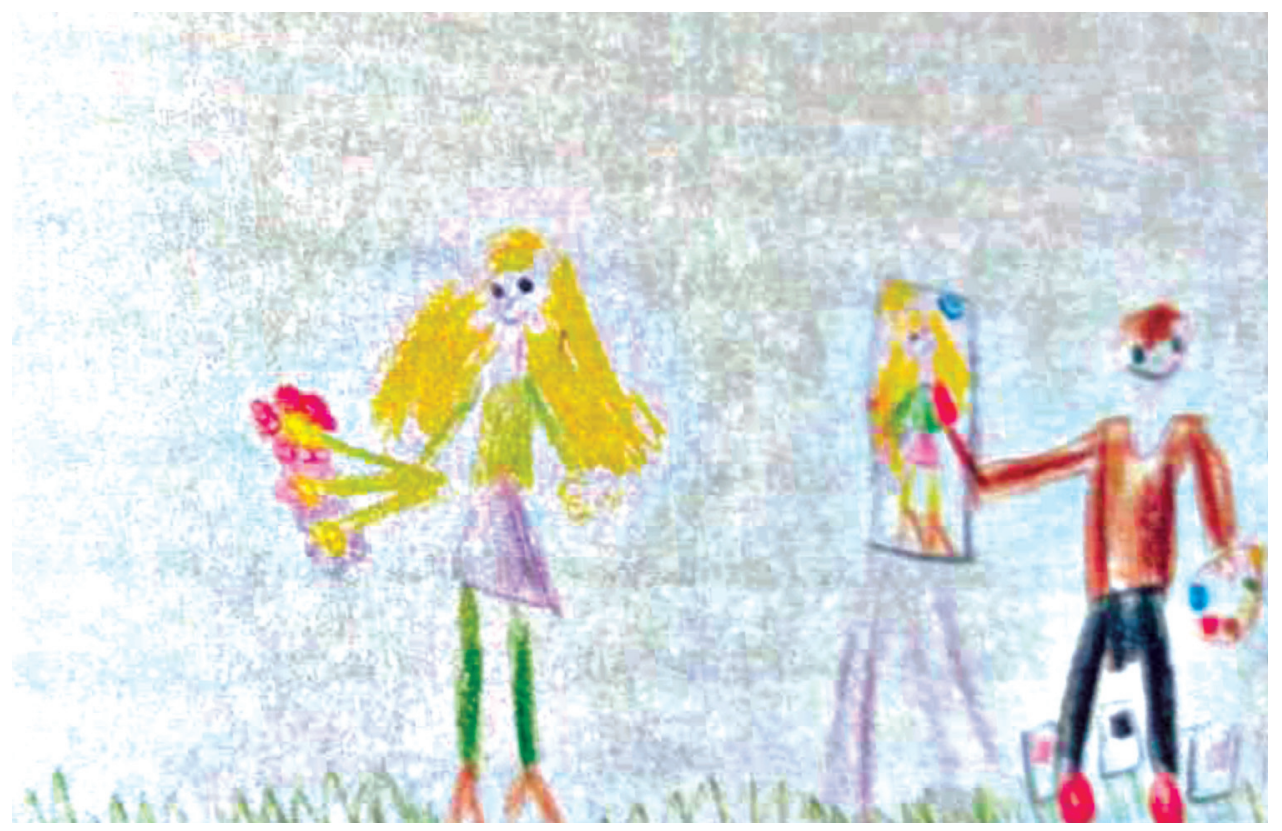

\section{Drawing 1. Marta, 7 years old}

Marta's work gives the impression of being subordinated to the aesthetic effect. Also, the interview with the author of the drawing confirms her tendency towards aesthetization:

B: why does Zuzia keep flowers?

MA: to be nicer, because it is a decoration.

In the next part of the interview, the girl again uses the aesthetic category, explaining the satisfaction depicted on the artist's face - it is a joy from performing "a nice" work. The meaning of the word "artist" is not interesting for a girl, it refers to the figure of a painter who paints pictures - most likely in a very nice and decorative way. 


\section{DISCUSSION OF RESEARCH FINDINGS}

In the sphere of adults "an artist" is a term whose meaning is not always clear, is subject to change and modifications, evolves with the broadly-understood culture, and it is also influenced by the type of social world a given person is connected with. There is, however, a certain scope of meanings that is commonly understood as the designata of the word "artist", which, although not always equally evaluated, does not raise doubts as to their correct identification. In the world of children the differences are more numerous, and the ease of adaptation of the learned concepts allows them to create the wealth of personal theories and beliefs.

The conducted research shows the diversity of the types of meanings that children 7 years old attribute to the term "artist". The ideas on this subject created by children prove to be a collection of beliefs of a partially common and often completely different nature. For a pedagogue, the ultimate purpose of the research, is to obtain knowledge which will allow effective changes in education, in this case, in art education. The investigation of meanings which children attribute to concepts concerning the artistic phenomena may allow to create a strategy of transmission of knowledge of art history and to design the creative activities connected with the broadly-understood visual arts.

The picture which emerges from the analysis of children's drawings and the contents of the interviews done with them makes one think. Children identify artistic activity in a narrow and limited way, "an artist" is almost always a painter, sometimes a sculptor, other types of possible activity in this field are almost unknown. Moreover, this figure is a strongly stereotypical creation, has no relation to the real events or situations we can encounter in life. It is a type of the learned idea, a concept whose representation remains beyond the possibility of everyday perception. There occurs a paradox here - for a number of decades the boundary between the popular art and the elitist art has been blurring due to the technological development, completely new art fields emerge, its manifestations are easily identified in everyday life. The work of designers, graphic designers, copywriters, industrial designers, architects or illustrators is visible at every step. At the same time, the interviewed children remain completely unaware of the existence of the world of contemporary art, learning the largely limited conceptual model of "high" art in a few stereotypical manifestations. Museum art is presented in an unattractive manner as alien and not too understandable space, whereas its other manifestations are omitted altogether.

From the point of view of pedagogical research one should take a closer look at the actions taken by the school in this respect. Art education in schools in the form 
it is conducted today fails to provide children with greater opportunity to develop a more open attitude towards "artistry". Textbooks and tasks in the early school education fail to give the students an opportunity to reach beyond the schematic and imitative mode of visual artistic expression. Similarly as in other spheres of education, children rarely have to do with free speech or an experiment.

Visual artistic activities are subjected to the improvement of graphomotor skills and often are limited to the instructions of "color", "complete", "complete the drawing”, "cut out and glue together”, “design” (according to the provided procedure).

Leaving the contents of textbooks aside, their graphic design may also raise doubts. In majority of cases the illustrations contained in those textbooks fail to go beyond the banal "children" esthetics in which it would be futile to try to find any artistic values. It appears that it is a lost opportunity to allow the child a continuous access to graphic materials of artistic value, i.e., to the continuous contact with the graphic art in a simple and natural way.

It would be advisable to return to the tradition of employing the renown painters and cartoonists in the positions of illustrators of children's literature as it was done a few decades ago. As far as the illustrated children's book is reborn after a difficult period of adjustment to the functioning on the free market, a group of talented and acclaimed also abroad Polish illustrators has emerged, the educational publishing houses decide against commissioning their services.

Moreover, teachers with their attitude have an restraining effect on the free creative expression. They lack the awareness of the role of the influence of creativity on the child's general development, they fail to notice the long-term benefits and advantages of the undertaken authentically creative artistic tasks. Depreciation and marginalizing of such activities stems from various factors. Partly the poor visual art awareness of tutors is to blame, no knowledge of art, their own prejudices and limitations in its reception, their own negative educational experiences. Another reason can be the requirements of the core curriculum which imposes on teachers the obligation to prepare students to master specific competences, obtain knowledge and skills verified by tests, without leaving time for teachers to conduct the classes not directly related to the achievement of pre-imposed aims. In this respect then it is a fault of the education system. Children are then subjected to the training of drawing "nicely", sporadic painting on A4 sheets of paper and the innumerable tasks of creation small special forms according to set patterns and on the precisely specified topic ("the autumn hedgehog", "a bee”, "an alien” and the like). 
The conducted research shows that such form of presentation of "artistry" results in departure from spontaneous creation and the need to rely on the pattern, both in form and in content. Children, not understanding the role of an artist other that a creator of conventionalized message, adjust their own activities to the found pattern. This phenomenon is all the more depressing since for early-education stage children the open attitude, curiosity, willingness to be active and experiment, confidence in their own possibilities in the sphere of visual art activities is their natural disposition. The possibility of creation and expression, the wealth of significance of created artwork is at this developmental stage something at the same time easy and as necessary as oxygen. Badly-conducted art education brings sad consequences in later years. Students experience striking conviction of their own inability in this sphere, partly characteristic of age but intensified and solidly grounded by the extensive grading system and steering the visual art activities.

The analysis conducted proves seven-year olds to be very creative in their reading of meanings hidden in paintings. Children receive visual symbols assigning to them meanings pertaining to specific knowledge about the world, real and fictitious (Karczmarzyk, Wasilewska, 2013). Contact with a work of art, which is a difficult visual message, arouses child creativity and cognitive activity, and helps to organise knowledge about the social world. The symbolic message becomes a peculiar catalyst for cognitive processes - associating various experiences, organising and integrating knowledge (Karczmarzyk, Wasilewska, 2013, pp. 485-494). In this way child strategies of recognising and interpreting reality, both symbolic and real, become revealed.

What, then, causes adults not to treat children seriously? Why do they try to protect the child against the real world, against hard subject matter contained in paintings? Why do they substitute them with idealised plastic figures not having any troubles and smiling from schoolbooks or animated films for the youngest?

It may result from the schematic reasoning about the child as about a valuable plant which needs to be protected (Klus-Stańska, Szczepska-Pustkowska, 2009). Yet, this concern is not going in a good direction, but rather allows negative influences related to aesthetisation of the modern world reaching the little recipient both from the world of television and Internet as well as advertising tabloids placed at every street corner. This is why the child needs to be shown masterpieces of great masters from the earliest years of education. Topics contained in paintings may prove very instructive and prepare the child for interpretation of the world and reception of culture not being simple also to an adult. Maturity and comprehension of the surrounding world can be attained by the child by skilful reading of 
paintings with art full of expression, full of emotions and frequently hard issues, which, as a matter of fact, are an indispensable part of real life.

\section{CONCLUSIONS}

The diagnosis which emerges from the above-presented observations indicates the need of reflection on the validity of introduction of elements of art education to the early school education in the form in which it takes place nowadays. Reflection on the training of teachers in this field, on the extension and the change of contents of the core curriculum regarding art. It would be advisable to disseminate the knowledge of the importance of teaching children not only the visual art skills and knowledge of art but perhaps, primarily, a creative attitude as a personality trait where precisely art can serve as a wonderful tool.

The examples of activities conducted by various kinds of animators as well as organizations and institutions such as Zachęta Gallery, Spotlight Kids or Bunkier Sztuki Gallery may be interesting for the school. These are the workshops with artists who co-create with children projects with great impetus. The projects are art-related - principally concerning contemporary art. The form of their realization is the dynamic class in the especially prepared rooms, with access to diverse media, visual art materials where children are encouraged to use the available means freely, to get dirty, create spontaneous scenarios with the help of artists and educators-aficionados. In school circumstances this is clearly an utopia, impossible to realize as curriculum activity. It may however constitute a model giving a direction to the conducted classes, specify the philosophy of the proposed message. It appears that any change resulting in the departure from the fossilized patterns is a change for the better.

The conclusion that can be drawn from the research results is the following: the school should teach and subject to reflection its own actions in the sphere of education about "artists" and "artistry". The examples of activities conducted by various kinds of animators should be interesting for the school. It is necessary that the youngest generation should find their own place in the world of contemporary culture, whereas the school is a naturally predestined venue to facilitate this process. By the same token, actions should be undertaken in order to improve the formal visual art education and adjust it to the requirements and needs of contemporary recipient. 


\section{References}

Limont, W., \& Nielek-Zawadzka, K. (Eds.). (2005). Dilemmas of Art Education. Vol. 1. Art Education in the Face of Changes in Culture. Kraków: Oficyna Wydawnicza "Impuls”.

Eco, U. (2003). Dzieło otwarte. Forma i nieokreśloność w poetykach współczesnych. Warszawa: Czytelnik 2003.

Karczmarzyk, M. (2013). Selected Texbooks for Class 1 of Integrated Teaching - Gunter Kress and Theo van Leeuwen Visual and Verbal Analysis. Chowanna, 2/41, pp. 303-313.

Karczmarzyk, M., \& Wasilewska, A. (2013). Art in the Eyes of Six-year-old Children. Children’s Semantic Hypallages Regarding Paintings of Great Masters. Procedia - Social and Behavioral Sciences. Volume 106. 10 December, pp. 485-494.

Karczmarzyk, M., \& Wasilewska A., Malarstwo w oczach dzieci. Znaczenia nadawane wybranym obrazom Salvadora Dalego, Pabla Picassa, Jacka Yerki, Kultura i Wychowanie, No. 10 (2) 2015, p. 36-43.

Karczmarzyk, M. (2010). What do Children's Drawings Mean? The Meanings and Communication Potential of the Drawing of a 6-year-old Child. Gdańsk: UG.

Karczmarzyk, M. (2010). The 'Own Method’ of Analyzing Drawings of Children According to Charles Sanders Peirce Triad. Problemy Wczesnej Edukacji, 2/12, pp. 172-176.

Karczmarzyk, M. (2014). What do Children’s Drawings Mean?. Gdańsk: Wyd. Anwi.

Klus-Stańska, D., \& Szczepska-Pustkowska, M. (2009). Pedagogika wczesnoszkolna: dyskursy, problemy, rozwiq̨zania. Warszawa: Wyd. Akademickie i Profesjonalne.

Menzer, M. (2015). The Arts in Early Childhood: Social and Emotional Benefits of Arts Participation. A Literature Review and Gap-analysis. Washington: National Endowment for the Arts.

Peirce, Ch.S. (1997). Wybór Pism Semiotycznych. Warszawa: Znak-Język-Rzeczywistość. 